\title{
Way Forward for Teacher Professional Development in Kenya: Utilization of Performance Appraisal Reports
}

\author{
Damaris Kariuki, \\ Hellen Guantai,
}

Kenyatta University, Nairobi, Kenya

Doi:10.19044/esj.2020.v16n16p230 URL:http://dx.doi.org/10.19044/esj.2020.v16n16p230

\begin{abstract}
Performance appraisal in the education sector has attracted scholarly interests globally. This is because critical feedback obtained from performance appraisal reports could be used to inform professional development needs of teachers. The purpose of this study was to establish the extent to which performance appraisal reports informed professional development of teachers in public secondary schools in Kenya. The study objectives were to establish the extent to which performance appraisal reports are used to inform identified teacher professional development gaps and find out the challenges encountered in the utilization of performance appraisal reports in informing teacher professional development. Mixed methods research design was used. The target population comprised 70 Principals, 210 Heads of Departments and 210 teachers giving a total of 490 respondents. Stratified and simple random sampling techniques were used to select a sample size of 98 respondents. Questionnaires and interview schedule were used to collect data. Descriptive statistics were used to analyze quantitative data while qualitative data were analyzed thematically. The study established that performance appraisal reports were not being used to inform teacher professional development activities. This was occasioned by inadequate head teacher and heads of department capacity on their role in teacher appraisal and professional development and limited resources to put in professional development interventions at the school level. The study recommended adoption of enhanced mechanisms to obtain appraisal reports, collate them and identify areas of professional development intervention.
\end{abstract}

Keywords: Utilization, Performance Appraisal, feedback, Professional development 


\section{Introduction}

Teacher appraisal globally provides a meaningful mechanism that encourages professional learning and growth whose implication would be effective in enhancing teacher performance. The Teachers' Service Commission (TSC) envisaged that through the appraisal system teachers would be empowered through professional training once their performance gaps were identified. This would help them retain the lost glory of the teaching profession and earn public confidence as professionals. Dressler (2008) noted that teachers become defensive when their performance weaknesses were brought out instead of accepting feedback as constructive ground of possible improvement.

The process of teacher appraisal is designed to foster teacher development and identify opportunities for additional support where required but the irony is that despite the TSC rolling out an elaborate appraisal system teachers have not yet felt the impact of the evaluation outcomes. It is anticipated that information generated from appraisal reports is expected to inform the process of teacher development. However, in 2017, Kenya National Union of Teachers (KNUT) through its secretary general commented that the teacher appraisal system had failed. This consequently makes performance appraisal a critical issue that is at the heart of teacher professionalism. In order for the process of appraisal to enhance teacher learning and boost their confidence there is need for quality feedback and mutual reflection from all the key players.

According to Okumbe (1999) appraisal is an administrative strategy aimed at stimulating teachers towards greater pedagogic effectiveness and productivity. Further, performance appraisal provides a periodic review and evaluation of an individual's job performance and therefore timely disbursement of evaluation reports would add value to the quality of professional development programmes that are conducted. In 2017, Teachers Service Commission in its monitoring exercise observed instances of poor communication between appraiser and appraisee and this questions the authenticity and credibility of the reports given. The appraiser is ultimately responsible to initiate the conversations and ensure they are documented for utilization at a later date. It is therefore necessary to establish if the appraisal reports are used to inform teacher professional development.

The Teacher Performance and Development Tool (TPAD) introduced by TSC in 2014 was aimed at providing feedback and a corrective mechanism to identify training needs which in turn would inform teacher professional development. Though Donaldson and Donaldson (2012) report that teachers need constructive feedback from skilled practitioners in order to improve their teaching, research suggests that feedback is often not a common occurrence in schools (OECD, 2009, Zatynski, 2012). One of the seven competency areas in 
the TPAD tool is professional development of teachers. The TSC optimistically expects to realize improved teacher competencies and improved professional development from the performance appraisal. Consequently, the utilization of appraisal reports for teacher professional development is critical and that was the concern of this study.

Teachers are the most significant resource in schools in terms of raising education standards and ensuring efficiency and quality of schooling. However, for teachers to perform at their best, Santiago and Benavides (2009) note that it is imperative for the policy makers to establish mechanisms that ensure that teachers are highly skilled, well-motivated and well resourced. Effective monitoring and evaluation of teaching is central to continuous improvement of teachers' effectiveness through processional development. From this perspective, Owuor and Jonyo (2016) opine that performance evaluation of teachers in Kenya is a vital step in the drive to identify aspects of the practice which need further development. Similarly, Santiago and Benavides (2009) posit that performance appraisal is the evaluation of employees, providing them with valuable feedback and creating a positive effect on future performance and professional development. Nonetheless, employee performance depends upon several factors such as work profile, conducive work environment, job satisfaction, compensation, technology and organizational policies. These are indeed the parameters that the appraisal system mounted by the TSC seeks to get feedback on from all the teachers working in public schools in Kenya.

Teachers' Service Commission in 2016 through its Corporate Communication Division established that performance management is a systematic process of improving an institutions performance by developing individual performance targets and those of the teams. The TSC Handbook (2015) explains that Teachers Service Commission rolled out Performance contracting for head of institutions and Teacher Performance Appraisal and Development for all teachers. These tools were meant to enhance the quality of teaching and teacher development through implementation of appraisal reports. The TSC has clearly specified the parties who will be involved in performance appraisal. These are the TSC officers at the counties under patronage of county directors, sub-county directors and curriculum support officers. The implementing agents are head teachers, deputy head teachers and head of departments. Despite the fact that the purpose of the TPAD tool in Kenya is clearly defined, there are no frameworks on how the reports will be utilized in professional development of teachers. Meaningful teacher evaluation entails an accurate appraisal of the effectiveness of teaching, its strengths and areas for development, followed by feedback, coaching, support and opportunities for professional development. It is essential to recognize and reward the work of teachers after the appraisal process. However, most of the 
appraisal feedbacks obtained from the appraisal report are not used in professional development of teachers in Kenya and that then defeats the purpose of the whole appraisal process.

The process of teacher performance appraisal is a complex activity with various challenges. Some of the challenges highlighted by literature include the low level of understanding of performance appraisal process, inadequate training, time and resource constraints. According to Flecher (2000) low level of understanding can cause a lot of confusion among individual workers at all levels. Consequently, teachers may experience difficulties or fail to cope up with setting objectives and this affects implementation of the performance appraisal.

Performance appraisal involves a lot of activities from setting objectives to form filling and signing, therefore line managers as appraisers are supposed to have intimate knowledge of the appraisal process. This is in line with (Dessler, 2008) who opines that supervisors must be familiar with basic appraisal techniques, understand and avoid problems that can cripple the appraisal process. Kulvass (2007) further observes that it is beneficial to train both supervisor and supervisee since both are partners in the implementation of performance appraisal.

Research revealed the issue of credibility of the appraisal reports making it difficult for policy makers to identify areas that need professional development (Owuor \& Jonyo, 2016). This is due to the fact that appraisees who in this context are teachers most times over rate themselves giving a false impression about their capabilities. Consequently, their actual areas of weaknesses are seldom known.

Teachers Service Commission is also concerned that while it spent millions of shillings to train over 30,000 head teachers on TPAD system a tool used to assess and recommend teachers to be promoted, demoted, disciplined or appointed to the next grade most of these teachers are still unable to effectively use these tools. The TPAD has an arbitration space that ought to be signed when both the appraiser and appraise fail to agree on ratings and in the presence of an arbitrator. However, most teachers and their appraisers tend to fill this part even where there is no disagreement a fact that shows that teachers do not understand the tool.

Most teachers have a perception that TPAD is a time wasting activity thus making evaluators to falsify information on the weakness observed in the appraisee. Majority of Head of departments fail to face up to the responsibility of an honest assessment of a teacher's skills, abilities and performance. Some evaluators are prone to looking to the positive side of the appraisee teaching strategies and write glowing reports when they should report weakness that they know are present. In fact, Zhang and $\mathrm{Ng}$ (2015) observes that performance appraisals have become a ritual in schools and is not connected 
to teacher improvement and professional development. This makes the whole appraisal process questionable and the need to investigate if the reports are utilized for addressing teacher professional development needs in the background of the newly introduced Teacher Performance Appraisal and Development (TPAD) tool in Kenyan public schools.

\section{Problem statement}

Literature reviewed in the background demonstrates a positive relationship between appraisal feedback and effective teacher professional development. The background has further demonstrated that teacher appraisal feedback is essential in informing professional development of teachers. However, the reality is that despite the existence of teacher performance appraisal in Kenyan public schools, the utilization of the appraisal reports to inform teacher professional development is wanting. There is evidence of teachers not getting their timely evaluation reports and hence this puts their professional development into question.

\section{Research Design and Methodology}

This study employed concurrent mixed methods approach where both quantitative and qualitative data was collected. According to (Creswell 2013) convergent mixed methods design seeks to merge both quantitative and qualitative data on the same topic in order to provide a comprehensive analysis of the research problem The target population comprised 70 Principals, 210 Heads of Departments and 210 teachers giving a total of 490 respondents in Imenti Central, Meru County, Kenya. Stratified random sampling was used to select 4 county schools and 10 sub County schools. Stratified random sampling was used to sample $10 \%$ of the schools i.e. County and Sub county schools. Proportionate stratified and simple random sampling techniques were used to select a sample size of 84 heads of departments and teachers which was $20 \%$ of the target population. All the 14 principals in the sampled schools were included in the study. The study employed questionnaires and interview schedule for data collection.

\section{Discussion of findings}

The study first sought to find out teachers understanding of the TPAD as an appraisal tool and the results are presented in figure 1. 


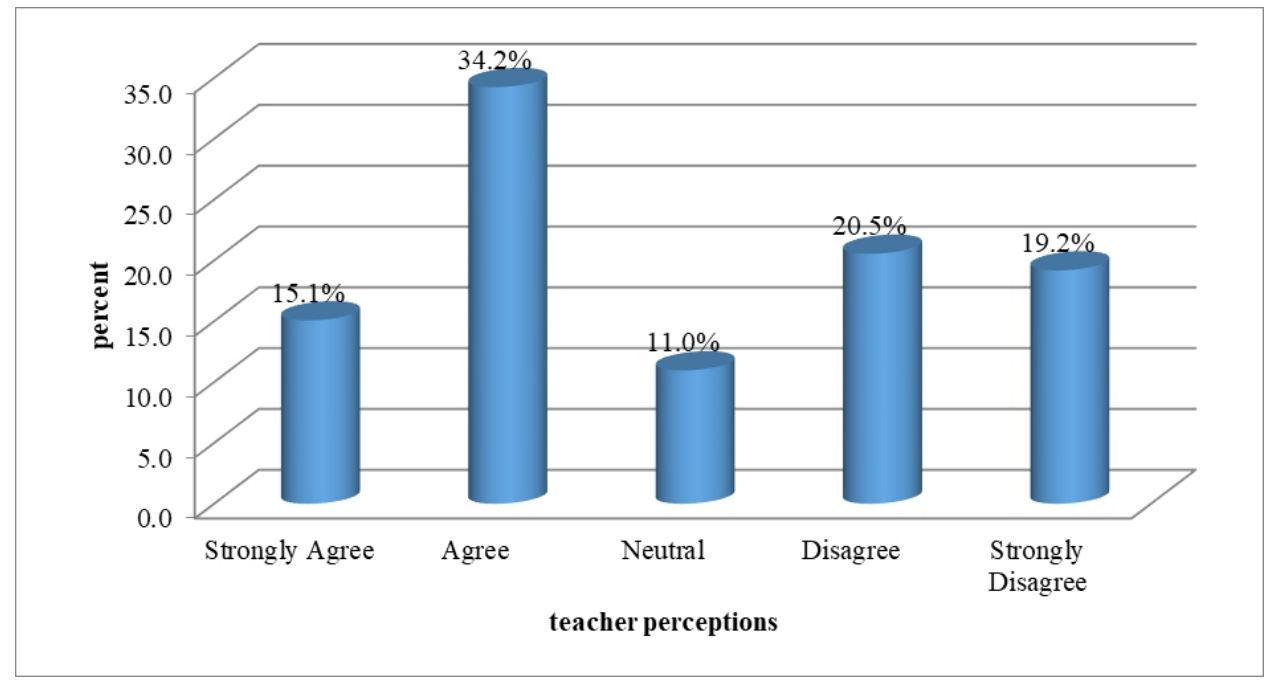

Figure 1: Extent to which teachers understand TPAD

Figure 1 reveals that $49.3 \%$ of the teachers indicated that they understood the Teacher Performance Appraisal and Development (TPAD) as an appraisal tool. The tool being significant in teacher performance appraisal needed to be understood by all the teachers so that it can generate information that can inform their professional needs. However, 39.7\% expressed the sentiment that they never understood what the TPAD tool and $11 \%$ were neutral yet the tool would be used to appraise them. This resonates well with one of the interviewed principal who expressed that majority of the teachers had no idea about the performance appraisal too yet the TSC had spent a lot of resources sensitizing them on the same. The principal said:

It is very unfortunate that most of the teachers seem not to understand the performance appraisal tool and the most unfortunate thing is that the TPAD will be used to inform their promotions. They take it casually.

The aspect of teachers not being able to understand the performance appraisal as a tool to appraise them concurs with Flecher (2000) who expressed that low level of understanding can cause a lot of confusion among individual workers at all levels. Consequently, teachers may experience difficulties or fail to cope up with setting objectives and this affects implementation of the performance appraisal. Armstrong (2003) avers that performance appraisal had become an annual ritual that it is taken casually in many countries.

The results of whether the appraiser shares feedback with the appraisee are presented in figure 2 . 


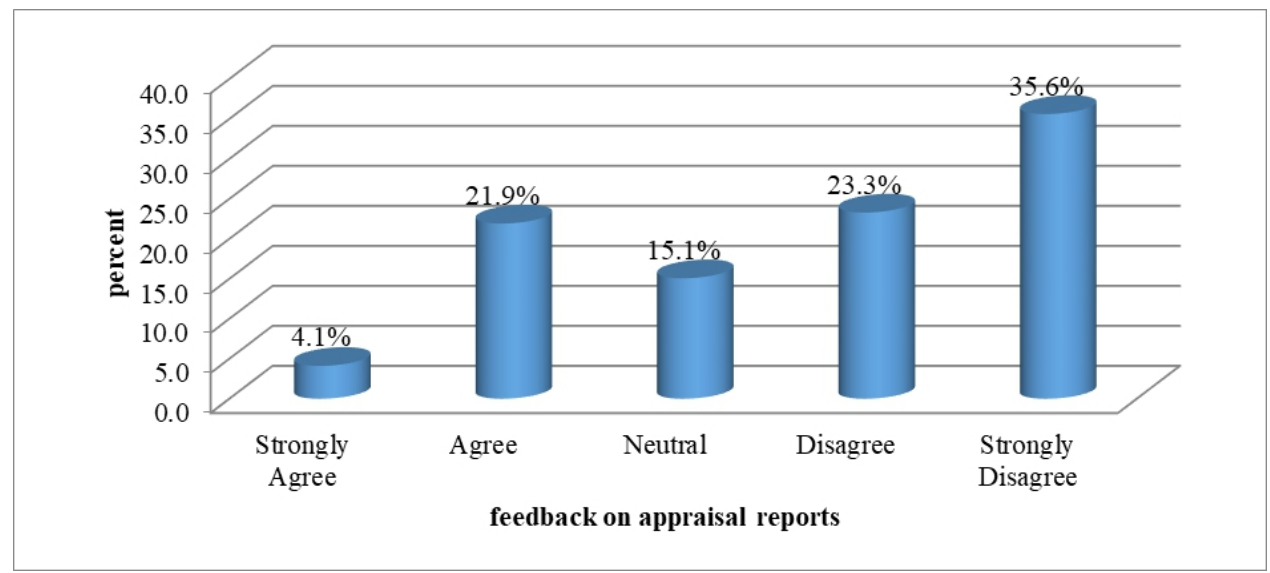

Figure 2: Extent of sharing feedback from appraisal reports

Figure 2 above shows that $58.9 \%$ of the respondents indicated that the performance appraisal feedback was not shared with them yet it was meant to address their own professional gaps. The implication is that if the information was not shared it was questionable if the reports were utilized to inform their professional needs. The issue of credibility of the appraisal report makes it difficult for policy makers to identify areas that need professional development. Feedback is an important tool as positive feedback motivates the employees to do better while cases of performance below expectation offer an opportunity to address the deficiencies and therefore reinforce employee behaviour in terms of better performance (Cardy \& Leonard, 2011).

Indeed, it was clear from the interviews conducted that some teachers had never received any performance feedback

One of the head of department noted;

Sometimes, teacher performance appraisal is done as a formality. We never share these reports with the teachers and just hand in the forms to the head teacher. Most of times training is not done even if there was a need identified.

Nyatera (2011) observes that when the qualification and work of a performance assessor looks questionable, then the results of the appraisal process are also likely to be questionable.

According to OECD (2012), teacher performance appraisal feedback is critical as it motivates and directs teaching in school. Feedback assists teachers to learn their level of professional abilities and make appropriate adjustments for improved performance. This clearly shows the invaluable benefit of feedback in any appraisal system. A report by OECD (2009) confirmed that teachers did not receive their feedback quite often even in developed countries. In Ireland for example, only $27 \%$ of the teachers said 
they received their appraisal feedback while Portugal had 33\%. Gichuhi (2011) study in Kenya, showed that performance appraisal feedback was not disseminated for use in teacher development. There was therefore need to conduct thorough training needs assessment as well as teacher training.

The study further sought to establish whether the teachers received any form of support from their appraisers after being appraised and the results are presented in figure 3.

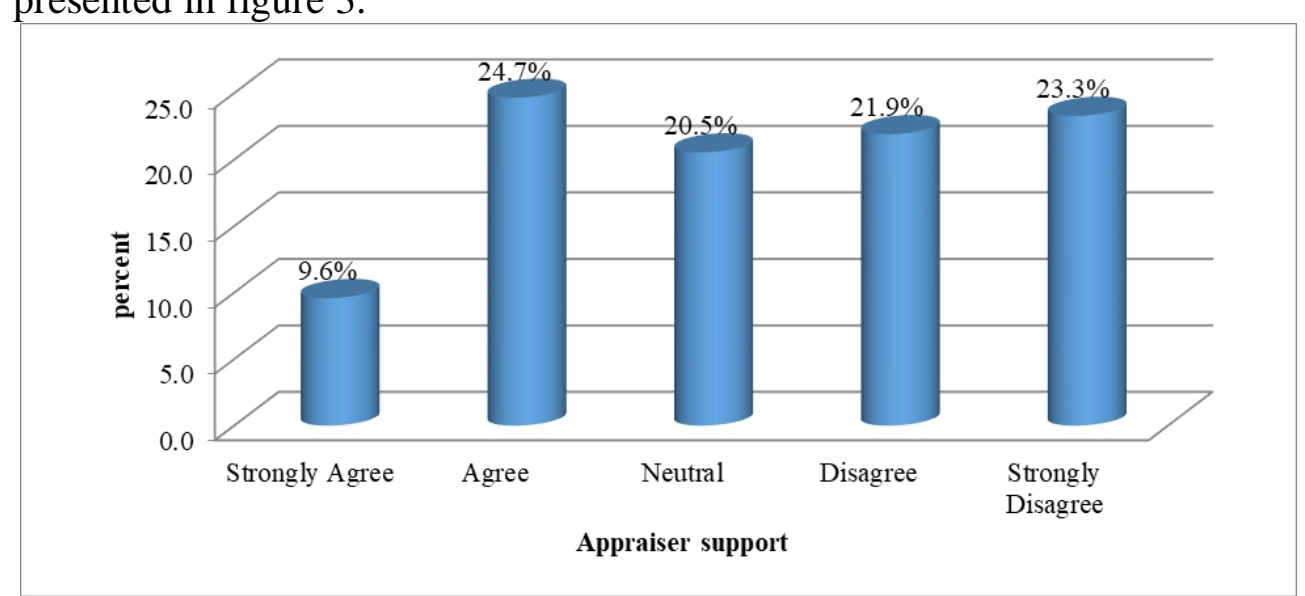

Figure 3: Extent of appraiser support

The results in Figure 3 reveal that $45.2 \%$ of the respondents reported that they did not received appraiser support while $20.5 \%$ were neutral. It is only $34.3 \%$ who indicated that they received support. This implies that process of post conference session after appraisal did not take place. The implication is that if the appraiser support was not received then it was difficult for them to utilize the reports for informing teacher professional development needs. One of the Head of Department expressed the sentiment that in many circumstances the teachers never received their feedback after appraisal and there were no clear means on how, when and who would solve the weaknesses identified. This sentiment agrees with Donaldson and Donaldson (2012) who report that teachers need constructive feedback from skilled practitioners in order to improve their teaching however, research suggests that feedback and support is often not a common occurrence in schools (OECD, 2009, Zatynski, 2012). The HOD went on to say, 'as a head of department, I have a heavy workload and for me this whole process is tedious and bothersome

The study finding revealed that most of the appraisers lacked the capacity to offer support to the appraisee even after identifying performance gaps. Flores (2010) in a study in Portugal found out that only $37.5 \%$ of the teachers indicated that their appraisers had the capacity to carry out the appraisal exercise making teachers question the credibility of the process. On the part of teacher support and professional development planning, the 
appraisee should be able to identify the gaps which hindered him/her from achieving the set goals while giving the recommended support/activities needed to improve on that target. Some appraisees however, were reported to leave the space blank making the whole process meaningless as the appraisers were not able to identify the teacher's professional needs. There are also instances where teachers were said to rate themselves on areas like technology even when the schools they work do not have the requisite resources like computers. The principals reported that such instances complicated the whole appraisal process and how it would be used to plan for teacher professional development support.

Kagema and Irungu (2018) study among secondary school teachers concluded that the appraisal system as currently structured did not offer the expected benefits to the appraisees.

Respondents were further asked to state whether appraisal feedback was used to develop a school support plan for the teachers. The results are presented in figure 4.

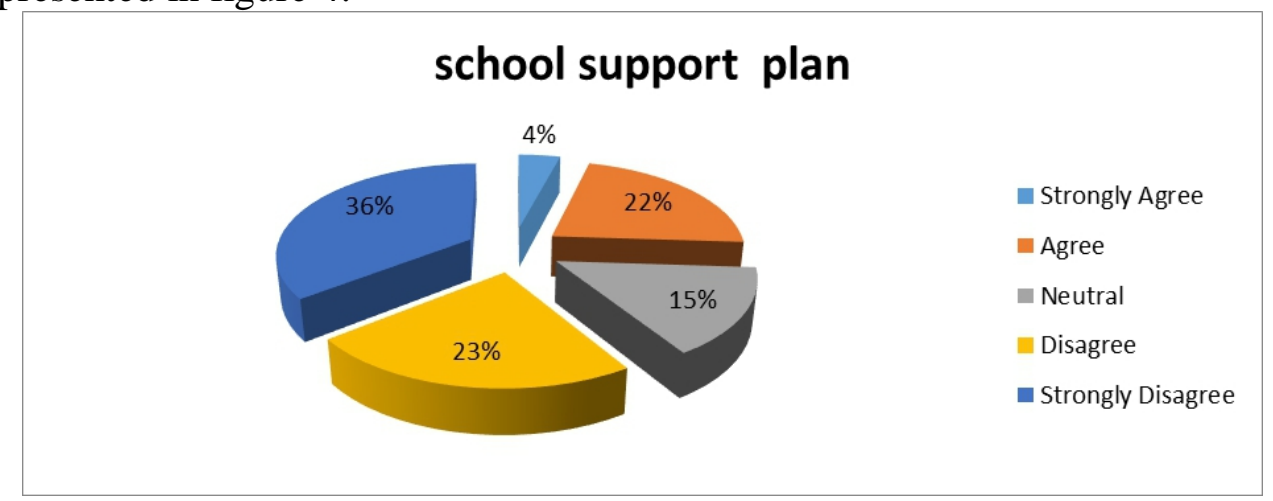

Figure 4: School support plan

It is evident from figure 4 that $59 \%$ of the respondents indicated that performance appraisal feedback was not used to inform school improvement plan with only $26 \%$ agreeing. This implies that the professional needs of the teachers would be in jeopardy since teachers comprise a critical resource in school improvement plan. Schools need to structure their support plan based on their staff needs some of which can be drawn from the appraisal reports Stronge (2010) suggests an appraisal system that has accountability and professional growth component where both appraiser and appraisee commit to plan for improvement of identified gaps is the ideal. This can be achieved by the schools having clearly designed support plans to address the identified performance gaps.

The principals' expressed their sentiments that even if the teacher performance appraisal process would be used to identify teachers' 
performance gaps, there were no resources to develop a school improvement plan and wondered;

Whose responsibility is it to train and improve the teachers? We could be willing as head teachers but we are strained by inadequate resources. The money set aside for seminars and training is never enough.

Findings from a study by Cory, Ward and Schultz (2007) showed that employees who receive support after an appraisal process indicate that such support contributes greatly in creation and generation of ideas.

The study sought to establish if performance appraisal reports were used to inform professional development needs of the teachers and the results are provided in figure 5 .

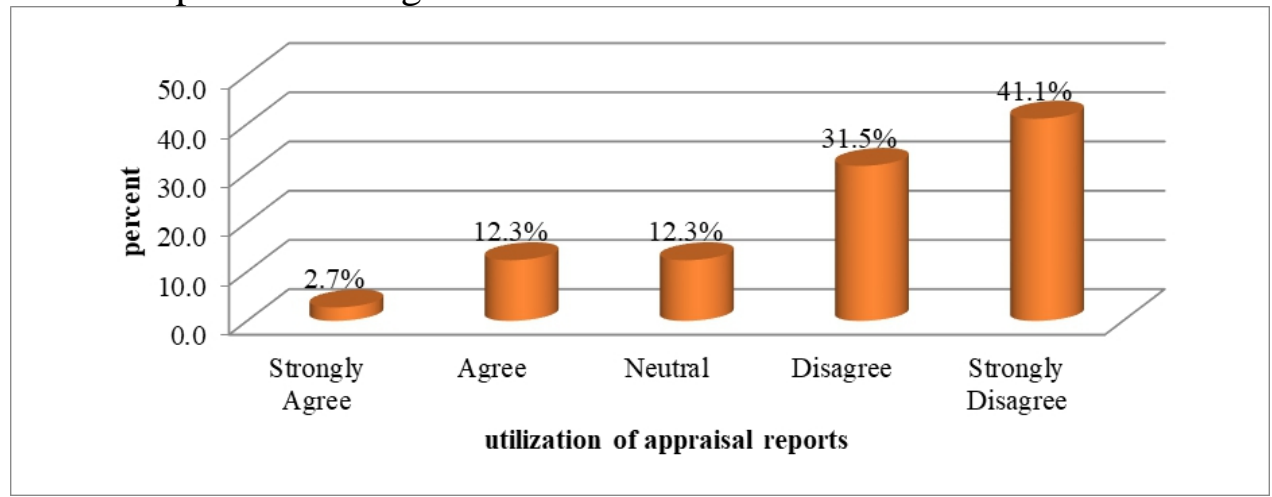

Figure 5: Utilization of appraisal reports

The findings in figure 5 reveal that $72.6 \%$ were of the view that performance appraisal feedback was not used to inform professional development needs of the teachers and this ideally beats the whole logic behind the introduction of this process. The utilization of the performance appraisal feedback is important because it is customized on the unique needs of each of the teachers and schools would stand to gain more if this was to happen. However, the sad reality is that this does not happen. This finding is corroborated by Owuor \& Jonyo, (2016) who question the credibility of the appraisal report making it difficult for policy makers to identify areas that need professional development because of the casual way in which it is done.

One of the HODs expressed that:

many times when we HODs undertake the teacher performance appraisal, we do not compile the reports. We simply give the report to the principal and are not involved in planning professional training of the teachers. 
Gardner (2008) describes performance appraisal as the evaluation of an employee's work with the main aim of arriving at objective personnel decisions. One key objective of performance appraisal is identification of employee strengths and weaknesses that form the basis of recommending actions for improved employee performance. One of these personnel decisions is planning for professional development of the employees through further training. According to the TSC (2012), one of the critical purpose of the teacher appraisal system is to assist in the identification of teachers' training needs and planning for professional development interventions.

A study by Gichuhi (2011) in Kenya found the appraisal system to be ineffective. He observed that the appraisal reports were not made reference to with regard to teacher in service training. Stronge (2010) asserts that teacher evaluation system should combine accountability and professional growth dimensions for it to be useful, effective and achieve the desired objectives. In his study Gatemi (2004) noted that only $30.6 \%$ of the teachers thought performance appraisal supported their career development while a majority $51.8 \%$ found performance appraisal not helpful in identifying and addressing their training needs. This is critical as it supports this study finding that the performance appraisal reports were not utilized to support teacher professional development needs. It therefore begs the question whether the performance appraisal tool was helpful in improving teacher quality through professional development interventions as envisaged by the TSC.

The second objective of this study was to determine the challenges in utilization of performance appraisal reports in informing professional development of teachers. Head teachers cited the huge cost implications and lack of adequate training as challenges that affected the process of teacher appraisal. One of the head teachers noted, 'yes, we were trained but it was not enough, there is need for regular refresher courses if the appraisal is to be done well and get the desired results.'

This finding concurs with Nyatera (2011) who revealed that head teachers were not trained to conduct performance appraisal, resulting to procedural mistakes and these influenced teachers to perceive their appraisal negatively. Wanzare (2002) in his study identified top-down approach, inadequate teacher evaluation and lack of appraisal feedback as some of the bottlenecks leading to ineffective teacher performance appraisal in Kenya.

Time constraint was also cited as a challenge by the head teachers as most of them lamented that they had a lot of administrative work and consequently delegated this vital responsibility to one of the senior members of staff. They said, 'this whole process is tedious yet I have both administrative and teaching loads. How effective can one be?'

As far as the HODs were concerned, some of the key challenges that were identified included heavy workloads, time constraints, resistance from 
some of the teachers and the negative attitude of the teachers towards the whole process. Dressler (2008) noted that teachers had a negative attitude and instead of accepting feedback as constructive ground of possible improvement they were defensive.

\section{Conclusion}

The study concludes that teachers did not fully understand the performance appraisal tool. The appraisers did not offer support to teachers to address their performance gaps due to limited capacity and time constraints. Schools did not have support plans for teachers after the appraisal process. Feedback from teacher performance appraisal was not used to inform teacher professional development activities therefore, teacher professional needs were not informed by the outcome of the appraisal reports. Effective teacher performance appraisal was affected by incapacity of the appraiser, limited resources, time constraints, heavy workloads and negative teacher attitudes towards the appraisal system.

\section{Recommendations}

This study recommends that the Teachers Service Commission needs to undertake constant sensitization campaigns to refresh the, principals, heads of departments and teachers on the appraisal process. This will assist to demystify the whole appraisal process. An effective tool for collating all the teacher performance gaps from the appraisal reports can be drafted to be used to plan for professional development activities to bridge the identified professional gaps. More resources can also be channelled towards supporting cost effective teacher professional development activities at the school level to address some of the identified professional development gaps.

\section{References :}

1. Armstrong, M. (2003). A handbook of Human Resource management practices (9th ed.). Philadelphia \& New Delhi: Kogan.

2. Cardy, L. \& Leonard, B. (2011). Performance Management: concepts, skills, and exercises. New Delhi: M.E Sharpe.

3. Cory, S.N., Ward, S. \& Schultz, S.A. (2007). Managing human resources in a small firm. Motivation through performance evaluation, The CPA Journal, 62-65.

4. Creswell, J. W. (2013). Qualitative Inquiry \& Research Design Choosing among Five Approaches (3rd ed.). Thousand Oaks, CA SAGE.

5. Dessler, G. (2008). Human Resource Management. (11th Ed). New Jersey: Pearson. Hall. 
6. Donaldson, M., \& Donaldson, G. (2012). Strengthening teacher evaluation: what district leaders can do. Educational Leadership, 69(8), 78-82.

7. Fletcher. C (2000) Appraisal: an idea whose time has gone: personnel management. New York Inc.: Harper and Row Publishers.

8. Flores, M. A. (2010). Teachers ${ }^{\text {ee }}$ performance appraisal in Portugal: the (Im) possibilities of a contested mode. Mediterranean Journal of Education studies 15(1), $4-60$.

9. Gardner, C.E. (2008). Employee evaluation: is it worth the effort? DVM, 18(5), 647-81.

10. Gatemi, M. W. (2004). The impact of appraisal on teachers' performance in Kenya: a case Study of girls' secondary school teachers in Nairobi Province. MBA thesis. Kenyatta University.

11. Gichuhi, D. M. (2011). The effects of performance appraisal on teachers' development: a Case of secondary school teachers of Laikipia West district, Kenya. Med, Thesis Kenyatta University.

12. Kagema, J., \& Irungu, C. (2018). An analysis of teacher performance appraisals and their influence on teacher performance in secondary schools in Kenya. International Journal of Education, 11(1), 93-98.

13. Kulvass, B. (2007). Different Relationships between Perceptions of Developmental Performance Appraisal and Work Performance. Personnel Review, 36(3), 378-397.

14. Nyatera, V. O. (2011). Head teachers and Teachers perceptions regarding staff Performance appraisal. Med, Kenyatta University.

15. OECD. (2013). OECD review of evaluation and assessment in education synergies for better learning. an international perspective on evaluation and assessment. Paris: OECD.

16. OECD. (2009). Teacher evaluation: a conceptual framework and examples of country practices. Paris: OECD.

17. OECD, (2009). School evaluation, teacher appraisal and feedback and the impact on school and teachers. Paris: OECD.

18. Okumbe, J. A. (1998). Educational Management: theory and practice. Nairobi: Nairobi University press.

19. Orodho, J. A. (2012). Techniques of writing research proposals and reports in education and social sciences. Nairobi: Kanezja Publishers.

20. Owuor, J.D \& Jonyo, B.O. (2017). Performance management in Kenyan public schools: implications and challenges. European Journal of Educational sciences, 4(3), 19-35.

21. Santiago, P. \& Benavides, F. (2009). Teacher evaluation. a conceptual framework and examples of country practices. Mexico City: OEDC.

22. Stronge, J. H. (2010). Evaluating teaching: a guide to current thinking and best practice (2nd ed.). Thousand Oaks, CA: Corwin Press. 
23. Teachers Service Commission, Kenya. (2015). Teachers' performance appraisal report. Nairobi: TSC.

24. Teacher Service Commission, Kenya. (2015). Annual report 2014/2015. Nairobi: TSC.

25. Teacher Service Commission, Kenya. (2015). TSC handbook. Government printer, Nairobi: TSC.

26. Teacher Service Commission, Kenya. (2012). Teachers Service Commission Act 2012. Nairobi: TSC.

27. Teacher Service Commission, Kenya (2016). Teacher performance appraisal and development: TPAD manual. Nairobi: TSC.

28. Zhang, X., \& Ng, H. (2015) An effective model of teacher appraisal: Evidence from secondary schools in Shanghai, China, Educational Management Administration and Leadership, 45(2), 196-218. DOI: $0.1177 / 1741143215597234$

29. Zatynski, M. (2012). Revamping teacher evaluation. Principal, 91(5), 22-57.

30. Wanzare, Z.O. (2002). Rethinking teachers' evaluation in the third world. Educational Management and Administration, 30(2), 213 229. 